\title{
Study of Comparison of Dexmedetomidine Added to Levobupivacaine versus Alone Levobupivacaine in Supraclavicular Brachial Plexus Blockade
}

\author{
Nimisha Brahmbhatt ${ }^{\circledR 1}$, Swati Mehta ${ }^{\circledR 2}$ \\ ${ }^{1}$ Associate Professor, Department of Anaesthesia, Government medical College, Baroda, Gujarat, India, ${ }^{2}$ Ex Resident, Department of Anaesthesia, Government \\ medical College, Baroda, Gujarat, India.
}

\section{Abstract}

Background: The aim is the current research is the comparison of Dexmedetomidine added to Levobupivacaine versus alone Levobupivacaine in supraclavicular brachial plexus blockade. Subjects and Methods : The current research was performed in the Department of Aneshtesia, Government Medical College and SSG Hospital, Vadodara, from October 2014tooctober to 2015. Subjects were separated into 2 groups: Group LD: receives Inj. Levobupivacaine $0.5 \%(35 \mathrm{ml})+$ inj.Dexmedetomidine $(0.51)+\operatorname{Inj} . \mathrm{NS}(0.5 \mathrm{ml})=$ total $36 \mathrm{ml}$. Group L: receives Inj.Levobupivacaine0.5 $\%(35 \mathrm{ml})+$ inj. Normal saline $(1 \mathrm{ml})=36 \mathrm{ml}$. Pulse rate, Blood pressure, Respiratory rate and Oxygen saturation $\left(\mathrm{SpO}_{2}\right)$, Ramsay sedation score were monitored before giving the block, immediately after giving the block, each 5 minutes till fifteen minutes, every fifteen minutes thereafter for one hour and each thirty minutes afterward until the conclusion of surgery. Results: Total duration of sensory block was significantly extended in group LD as a contrast to group L. Total duration of motor block was significantly longer in group LD as a contrast to group L. Patients receiving Dexmedetomidine had long-lasting postoperative analgesia as compared to the control group. Thus, the total duration of analgesia was considerably extended in group LD patients as a contrast to group L patients and the dissimilarity was statistically highly significant. Conclusion: Dexmedetomidine can be utilized as a secure and useful aid to local anesthetics in supraclavicular brachial plexus block to give outstanding perioperative analgesia with negligible consequences.

Keywords: Analgesia, Dexmedetomidine, Levobupivacaine, supraclavicular brachial plexus

Corresponding Author: Nimisha Brahmbhatt, Associate Professor, Department of Anaesthesia, Government medical College, Baroda, Gujarat, India.

E-mail: nimishabrahmbhatt7@gmail.com

Received: 24 June 2020

Revised: 25 July 2020

Accepted: 31 August 2020

Published: 16 December 2020

\section{Introduction}

Pain is an enigma to the whole of mankind. One of the primary aims of anaesthesia is to render the patient pain free thereby permitting the performance of surgical procedures without discomfort. ${ }^{[1]}$

Regional anesthesia has outnumbered the quality of care and postoperative analgesia in various surgeries. The concept of regional analgesia existed since 1880 but has gained momentum in recent years. In 1911, Kulenkampff in Germany executed the primary percutaneous supraclavicular block. ${ }^{[2,3]}$ Patients who are administered regional anaesthesia may require adjuvant drugs to allay the anxiety observed during the peri-operative period. Such anxiety is caused by: Inability to move the body for a prolonged period gets a sense of uneasiness in many of the patients. ${ }^{[4,5]}$
Various drugs might be utilized as an aid to local anaesthetics to lesser doses of every agent and improve analgesic efficacy, to achieve quick, dense and prolonged postoperative analgesia while dropping the occurrence of adverse reactions.

Dexmedetomidine has been proved to advance the excellence of anesthesia and perioperative analgesia when administered as an aid to local anesthetics in intravenous regional anaesthesia without any significant side - effects. ${ }^{[6,7]}$ Even though the abolition half-life of Dexmedetomidine is little, the analgesicsparing outcome observed following preoperative or intraoperative management regularly lasts up to 24 hours, with the anxiolytic, sedative, and thymoanaleptic properties concerned as being somewhat accountable for this effect. ${ }^{[8-10]}$

Levobupivacaine has been utilized at every site: Accordingly of its lesser cardiac and neurotoxicity contrast to bupivacaine, treating doctors experience secure functioning with levobupi- 
vacaine, compare to bupivacaine. ${ }^{[11]}$

Considering the pharmacological profile of Dexmedetomidine, various reports of its efficacy and safety as an adjuvant to regional anaesthesia and very few studies of the combination of Dexmedetomidine with Levobupivacaine available in India, hence, the present research was performed to evaluate the effects of the addition of Dexmedetomidine to Levobupivacaine in supraclavicular brachial plexus block and observe the parameters like quality of anaesthesia, duration of analgesia, hemodynamic changes and possible complications. ${ }^{[12-17]}$

\section{Subjects and Methods}

The current research was performed in the Department of Anesthesia, Government Medical College and SSG Hospital, Vadodara, during October 2014tooctober 2015.

Ethical approval was obtained from the institutional ethical committee and informed consent was taken from every single member. The sample size was designed using a t-test with $\alpha$ error of 0.05 and $\beta$ error of 0.2 were used to compare the two groups. The minimum adequate sample size with these figures comes out to be 34 in each group, hence we will study a total of 70, 35 patients in each group.

\section{Inclusion criteria:}

Patients having Age group-18 to 60 years of each gender, belongs toASA-I/II, Planned/emergency surgery, Orthopaedic surgeries of the forearm, elbowand Patient able to give written informed consent

\section{Exclusion criteria:}

Patient is on alpha2 agonist/antagonist drug, ACE inhibitors, beta-blockers, calcium channel blockers, antiarrhythmics, digoxin, Hypersensitivity to local anesthetic drug and Patient with major systemic diseases.

\section{Pre Anesthetic Check-Up}

All patients underwent a thorough pre-anesthetic checkup which incorporated thorough history taking, general examination and systemic examination. Routine investigations like Haemoglobin, blood urea, serum creatinine, random blood sugar, ECG, chest X-ray, bleeding time and clotting time were carried out for every patient.

\section{Patients were divided into 2 groups}

Group LD: receives Inj. Levobupivacaine $0.5 \%(35 \mathrm{ml})+$ inj. Dexmedetomidine $(0.5 \mathrm{l})+\operatorname{Inj}$. NS $(0.5 \mathrm{ml})=$ total $36 \mathrm{ml}$

Group L: receives Inj.Levobupivacaine $0.5 \%(35 \mathrm{ml})+$ inj. Normal saline $(1 \mathrm{ml})=36 \mathrm{ml}$

On the day previous to surgery: The patient was kept zilch by mouth for 10 hours and Tablet Ranitidine (150mg) on the night previous to surgery. On surgery day: (in the recovery room) Following base-line parameters were obtained:
- Pulse rate

- Blood pressure

- Respiratory rate

- $\mathrm{SpO} 2$

- Ramsay Sedation Score

IV line was secured and 5\% Dextrose pint was started. The patient has explained the procedure to be performed. On the day of surgery: (in operation theatre), Multipara monitor was attached. Premedication: the patient was not given any medication.

The brachial plexus block was given following systematic clarification of the process and highlighting the requirement for patient assistance. The onset of sensory and motor block was measured each minute following the end of the injection of drugs till peak effect occurs.

Pulse rate, Blood pressure, Respiratory rate and Oxygen saturation $\left(\mathrm{SpO}_{2}\right)$, Ramsay sedation score were monitored before giving the block, immediately after giving the block, each five minutes till fifteen minutes, every fifteen minutes thereafter for one hour and each thirty minutes subsequently till the end of surgery.

Complications either due to procedure or anaesthetic drugs were looked for in the peri-operative period: Postoperatively the similar vital parameters were observed instantly following the conclusion of surgery, afterward whenever we visited the patient for note down the consequence of block and VAS score.

Sensory block assessed by pinprick method (using the tip of 23G needle).

The assessment was done beside the allocation of the median nerve, radial nerve, ulnar nerve and musculocutaneous nerve as follows:

- Median nerve: Thenar eminence

- Radial nerve: Lateral side of the dorsum of the hand

- Ulnar nerve: Little finger

- Musculocutaneous nerve: Lateral border of a forearm over the site of the radial artery.

Onset time: Time interval from the end of injection of a drug to loss of sharp pinprick pain sensation on anyone nerve territory.

Peak effect time: Time interval from the end of injection of a drug to loss of sharp pinprick pain sensation on all nerve territory.

Duration of sensory block done using 3 point scale: ${ }^{[13]}$

Motor block: Assessment of motor block was done as follows:

- Radial nerve: Thumb abduction, extension at elbow and wrist

- Median nerve: Thumb opposition 


\begin{tabular}{|c|c|c|c|}
\hline Parameters & Group LD & Group L & p-value \\
\hline $\begin{array}{l}\text { Number of } \\
\text { patients }\end{array}$ & 35 & 35 & $>0.05$ \\
\hline $\begin{array}{l}\text { Age (in } \\
\text { years, } \\
\text { Mean } \pm \text { SD) }\end{array}$ & $34.69+9.80$ & $38.89+12.15$ & $>0.05$ \\
\hline $\begin{array}{l}\text { Weight } \\
\text { (in } \mathrm{kg} \text {, } \\
\text { Mean } \pm \mathrm{SD} \text { ) }\end{array}$ & $52.17 \pm 2.3$ & $51.1 \pm 2.29$ & $>0.05$ \\
\hline $\begin{array}{l}\text { Gender } \\
\text { (Female; } \\
\text { Male) }\end{array}$ & $11 / 24$ & $8 / 27$ & $>0.05$ \\
\hline
\end{tabular}

- Ulnar nerve : Thumb adduction

- Musculocutaneous nerve: Flexion at the elbow

Onset time: Time interval from the end of injection of a drug to the onset of grade 1 motor block.

Peak effect time: Time interval from the end of injection of a drug to complete (Grade 2) motor blockade.

\section{Duration of motor block done using a modified Bromage scale: ${ }^{[18]}$}

Effect of sensory and motor block and postoperative analgesia (Visual Analogue Score - VAS) was measured every Thirty minutes for the first hour, every sixty minutes after that six hours and next at $8,10,12,18$ and 24 hours. The pain was measured using 10 points Visual Analogue Score - VAS.

Rescue analgesia was given in the type of Inj. Diclofenac Sodium $1.5 \mathrm{mg} / \mathrm{kg}$ intramuscularly when the VAS score was noted as $\geq 4$.

The time when rescue analgesia was noted and the total number of times analgesics were needed over 24 hours was also noted.

\section{Statistical Analysis}

All the data obtained was properly tabulated results were expressed as Mean $\pm \mathrm{SD}$. All the data were analysed using the chi-square test and unpaired t-test correspondingly and the pvalue is calculated. The significance test was done using SPPS version 15 software.

\section{Results}

The present research was performed to assess the study of comparison of dexmedetomidine added to levobupivacaine versus alone Levobupivacaine in supraclavicular brachial plexus blockade.

The number of patients in either group was 35 . The mean age of patients was 34.69+9.80years in group LD and
$38.89+12.15$ years in group L. $(\mathrm{p}>0.05)$.

The ratio of male: female was 24:11 in group LD and27:8 in group L ( $p>0.05$ : not significant). The mean weight of patients was $52.17 \pm 2.3 \mathrm{~kg}$ in group LD and $51.1 \pm 2.29 \mathrm{~kg}$ in group L. $(\mathrm{p}>0.05)$ [Table 1].

The mean duration of sensory block was $870.74+25.33$ minutes in group LD as compared to577.57+21.73minutes in group L. Thus, the total duration of sensory block was significantly extended in the group LD as compared to group $\mathrm{L}$ ( $\mathrm{p}<0.0001$ : highly significant) [Table 2].

[Table 3] describes the mean duration of motor block was $467.91+15.50$ minutes in group LD and580.57+21.73 minutes in group L. Thus, the total duration of motor block was significantly higher in group LD as a contrast to group L $(\mathrm{p} \leq 0.05$ : highly significant).

According to [Table 4], in group LD, all patients (100\%) were found to be Asleep; brisk response to a light glabellar tap or loud noise i.e. had a Ramsay sedation score of 4 . Whereas all patients in group $\mathrm{L}$ were found to be awake, co-operative, oriented and tranquil.e. had a Ramsay sedation score of 2 . In group L, none of the patients received supplementary sedation as they all were with Ramsay sedation score 2.

The total duration of peri-operative analgesia was 1078.03 \pm 24.46 minutes in group LD and $856.29 \pm 24.65$ minutes in group L. VAS score reached a value of 4 at the end of856.29 \pm 24.65 minutes in control group L whereas it took $1078.03+24.46$ minutes for the VAS score to reach a value of 4 in subjects who received Dexmedetomidine as an aid to supraclavicular block. Thus patients receiving Dexmedetomidine had prolonged postoperative analgesia as compared to the control group [Table 5].

Thus, the total duration of analgesia was significantly extended in group LD patients as compared to group L patients and the difference was statistically highly significant. ( $p$ $<0.0001$ : highly significant). The patients in group LD maintained a lower pulse rate during the perioperative period and bradycardia was observed in 3 patients out of 35 which was managed with a single dosage of Inj. Atropine $0.6 \mathrm{mg}$ IV. None of the patients in group $\mathrm{L}$ experienced bradycardia. No other complications were observed in both groups $(\mathrm{p}<0.001)$.

\section{Discussion}

It has always been forever hunting for adjutants to regional nerve block with drugs that extend the duration of analgesia but with slighter side effects. ${ }^{[12-14]}$ For many years, Clonidine, $\alpha$ 2-adrenergic receptor ( $\alpha$ 2-adrenergic) agonist, is extensively utilized as an analgesic adjuvant in perioperative circumstances and pain treatment. Dexmedetomidine is at present on the whole strong $\alpha$ 2-adrenergic agonist available and it 


\begin{tabular}{|c|c|c|c|}
\hline Time in minutes & $\begin{array}{l}\text { Group LD } \\
\text { patients) }\end{array}$ & Group L (no of patients) & Intergroup p-value \\
\hline $361-480$ & 0 & 0 & \\
\hline $481-600$ & 0 & 34 & \\
\hline $601-720$ & 0 & 1 & \\
\hline $721-1080$ & 35 & 0 & \\
\hline Mean \pm SD & $870.74+25.33$ & $577.57+21.73$ & $<0.0001$ \\
\hline
\end{tabular}

\begin{tabular}{|llll|}
\hline \multicolumn{2}{l}{ Table 3: Total Duration of Motor Block } & & \\
\hline Time in minutes & Group LD (no of patients) & Group L (no of patients) & Intergroup p-value \\
\hline $361-480$ & 0 & 33 & \\
$481-600$ & 34 & 2 & \\
$601-720$ & 1 & 0 & \\
$721-1080$ & 0 & 0 & $<0.0001$ \\
\hline Mean \pm SD & $580.57+21.73$ & $467.91+15.50$ & \\
\hline
\end{tabular}

Table 4: Patients with different Ramsay sedation score

\begin{tabular}{|c|c|c|c|}
\hline $\begin{array}{l}\text { Ramsay sedation score } \\
\text { (intraoperatively) }\end{array}$ & Group LD (no of patients) & Group L (no of patients) & Intergroup p-value \\
\hline 1 & 0 & 0 & \\
\hline 2 & 0 & $35(100 \%)$ & $<0.001$ \\
\hline 3 & 0 & 0 & \\
\hline 4 & $35(100 \%)$ & 0 & $<0.001$ \\
\hline 5 & 0 & 0 & \\
\hline 6 & 0 & 0 & \\
\hline
\end{tabular}

Table 5: Total Duration of Analgesia (in minutes) (Mean \pm SD)

\begin{tabular}{|llll|}
\hline Time in minutes & Group LD & Group L & Intergroup p-value \\
\hline $361-480$ & 0 & 0 & \\
$481-600$ & 0 & 0 & \\
$601-720$ & 0 & 0 & \\
$721-1080$ & 21 & 35 & \\
$1080-1440$ & 14 & 6 & $<0.0001$ \\
\hline Mean \pm SD & $1078.03+24.46$ & $856.29+24.65$ & \\
\hline
\end{tabular}

shows a promising future as an adjuvant to regional anaesthesia with good hemodynamic stability and arousable sedation without compromising the airway. ${ }^{[15,16]}$ Supraclavicular block has various advantages over other approaches of brachial plexus block like It can be performed without much manipulation of arm position and the block is executed where the plexus is mainly compact making it suitable for uniform anaesthesia or analgesia of the upper limb. Hence, in the current study supraclavicular technique of brachial plexus block was selected.
The study was performed in 70 patients undergoing planned/emergency forearm surgeries under supraclavicular brachial plexus block. This assortment associate with the study by Esmaoglu A et al (2010), Swami SS et al (2012). ${ }^{[17,18]}$

The mean age of patients was $34.69 \pm 9.80$ years in group LD and $38.89 \pm 12.15$ years in-group L. No significant difference between the mean ages of the two groups. Various other authors have used almost similar age groups in their studies, like - Esmaoglu A et al (2010), Gandhi R et al (2012). ${ }^{[17,19]}$ 
Meantime for onset of sensory block was $0.57+0.069$ minutes in group LD and $1.71+0.32$ minutes in group L. Patients receiving Dexmedetomidine had significantly prior beginning of sensory block as compared to the control group, which were by studies conducted by Swami SS et al, Kaygusuz K et al and Gandhi R et al. ${ }^{[18-20]}$

The mean duration of sensory block was $870.74+25.33$ minutes in group LD as compared to $577.57+21.73$ minutes in group L, so in group LD, patients get an extended duration of the sensory block as compared to Group L. Findings of this study agree with studies conducted by Swami SS et al, Kaygusuz $\mathrm{K}$ et al and Gandhi $\mathrm{R}$ et al. ${ }^{[18-20]}$

The mean time for peak effect of motor block was $4.95+0.41$ minutes in group LD and $12.74+1.07$ minutes in group L. The mean duration of motor block was $580.57+21.73$ minutes in group LD and 467.91+15.50minutes in group L which were in agreement with studies of Kayagusuz $\mathrm{K}$ et al and Gandhi $\mathrm{R}$ et al.

Mean postoperative diastolic blood pressure was $73.44 \pm 5.84$ $\mathrm{mm} \mathrm{Hg}$ in group LD as compared to $78.64 \pm 5.48 \mathrm{~mm} \mathrm{Hg}$ in group L. The difference between these two was highly significant $(p<0.001)$. These findings were following those of Esmaoglu A et al (2010), Gandhi R et al (2012), Kaygusuz $\mathrm{K}$ et al (2012) and Swami SS et al (2012).

There was no significant change in mean respiratory rate and oxygen saturation from its preoperative value at any given time of the study.

In group LD, all patients were found to be Asleep; quick response to a light glabellar tap or loud noise i.e. had a Ramsay sedation score of 4 . Whereas all patients in group $\mathrm{L}$ were found to be awake, co-operative, oriented and tranquil i.e. had a Ramsay sedation score of 2 . These findings were in agreement with Kaygusuz K et al (2012).

VAS score reached a value of 4 at the end of $12 \mathrm{hrs}$ in control group L whereas it took 18 hours for the VAS score to reach a value of 4 in patients who received dexmedetomidine as an adjuvant to supraclavicular block.

The results of our study demonstrated that in group LD, $100 \%$ of patients required one dose of supplemental analgesia within the first 24 hours post-operatively, Whereas in group L, $2(5.71 \%)$ patients required 1 dose of analgesia and the rest $33(94.29 \%)$ required 2 doses of analgesia in 24 hours postoperative duration.

\section{Conclusion}

Dexmedetomidine can be utilized as a secure and effectual aid to local anaesthetics in supraclavicular brachial plexus block to offer outstanding perioperative analgesia with negligible side effects.

\section{References}

1. Lakhlani PP, MacMillan LB, Guo TZ, McCool BA, Lovinger DM, Maze M, et al. Substitution of a mutant 2a-adrenergic receptor via "hit and run" gene targeting reveals the role of this subtype in sedative, analgesic, and anesthetic-sparing responses in vivo. Proc Natl Acad Sci. 1997;94(18):9950 9955. Available from: https://dx.doi.org/10.1073/pnas.94.18. 9950.

2. Kaur M, Singh PM. Current role of dexmedetomidine in clinical anesthesia and intensive care. Anesth Essays Res. 2011;5(2):128-128. Available from: https://dx.doi.org/10. 4103/0259-1162.94750.

3. Ozalp G, Tuncel G, Savli S, Celik A, Doger C, Kaya M, et al. The analgesic efficacy of dexmedetomidine added to ropivacaine patient controlled interscalene analgesia via the posterior approach. Eur J Anaesthesiol. 2006;23(37):220 220. Available from: https://dx.doi.org/10.1097/00003643200606001-00790.

4. Bogra J, Kohli M, Kumar S, Gupta R, Verma R, Kushwaha J. Dexmedetomidine as an intrathecal adjuvant for postoperative analgesia. Indian J Anaesth. 2011;55(4):347-347. Available from: https://dx.doi.org/10.4103/0019-5049.84841.

5. Liu SS, Strodtbeck WM, Richman JM, Wu CL. A Comparison of Regional Versus General Anesthesia for Ambulatory Anesthesia: A Meta-Analysis of Randomized Controlled Trials. Anesth Analg. 2005;101:1634-1642. Available from: https://dx.doi.org/10.1213/01.ane.0000180829.70036.4f.

6. Memis D, Turan A, Raramanlioglu B, Pamukcu Z, Rurt I. Adding Dexmedetomidine to lidocaine for intravenous regional anaesthesia. Anesth Analg. 2004;98(3):835-875. Available from: https://doi.org/10.1213/01.ane.0000100680.77978.66.

7. Lin L, Guo X, Zhang MZ, Qu CJ, Sun Y, Bai J. Pharmacokinetics of dexmedetomidine in Chinese post-surgical intensive care unit patients. Acta Anaesthesiol Scand. 2011;55(3):359367. Available from: https://dx.doi.org/10.1111/j.1399-6576. 2010.02392.x.

8. Ebert TJ, Hall JE, Barney JA, Uhrich TD, Colinco MD. The Effects of Increasing Plasma Concentrations of Dexmedetomidine in Humans. Anesthesiol. 2000;93(2):382-394. Available from: https://dx.doi.org/10.1097/00000542-20000800000016.

9. Gertler R, Brown HC, Mitchell DH, Silvius EN. Dexmedetomidine: A Novel Sedative-Analgesic Agent. Bayl Univ Med Cent. 2001;14(1):13-21. Available from: https://dx.doi.org/10. 1080/08998280.2001.11927725.

10. Grosu I, Lavand'homme P. Use of dexmedetomidine for pain control. F1000 Med Rep. 2010;2:90. Available from: https: //dx.doi.org/10.3410/M2-90.

11. Arias MG, A G. Levobupivacaine:A long acting local anaesthetic, with less cardiac and neurotoxicity. Anaesthesia. 2001;56:331-341.

12. Brummett CM, Hong EK, Janda AM, Amodeo FS, Lydic R. Perineural Dexmedetomidine Added to Ropivacaine for Sciatic Nerve Block in Rats Prolongs the Duration of Analgesia by Blocking the Hyperpolarization-activated Cation 
Current. Anesthesiology. 2011;115(4):836-843. Available from: https://dx.doi.org/10.1097/aln.0b013e318221fcc9. doi:10.1097/aln.0b013e318221fcc9.

13. Esmaoglu A, Yegenoglu F, Akin A, Turk CY. Dexmedetomidine Added to Levobupivacaine Prolongs Axillary Brachial Plexus Block. Anesthesia \& Analgesia. 2010;111(6):1548-1551. Available from: $\quad$ https://dx.doi.org/10.1213/ane.0b013e3181fa3095. doi:10.1213/ane.0b013e3181fa3095.

14. Kaur M, Sahoo S, Vajifdar H, Kohli P, Kohli S. Brachial plexus block: Comparison of two different doses of clonidine added to bupivacaine. J Anaesthesiol Clin Pharmacol. 2013;29(4):491491. Available from: https://dx.doi.org/10.4103/0970-9185. 119147.

15. Gandhi R, Shah A, Patel I. use of dexmedetomidine with bupivacaine in brachial plexus block. Natl J Integr Res Med. 2012;2:67-69.

16. Chakraborty S, Chakrabarti J, Mandal M, Hazra A, Das S. Effect of clonidine as adjuvant in bupivacaine-induced supraclavicular brachial plexus block: A randomized controlled trial. Indian J Pharmacol. 2010;42(2):73-73. Available from: https://dx.doi.org/10.4103/0253-7613.64498.

17. Somvanshi M, Tripathi A, Sharma K, Samal R. A comparative study of clonidine and dexmedetomidine as an adjunct to bupivacaine in supraclavicular brachial plexus block. J Anaesthesiol Clinic Pharmacol. 2016;32:344-344. Available from: https://dx.doi.org/10.4103/0970-9185.188819.

18. Swami S, Ladi S, Keniya V, Rao R. Comparison of dexmedetomidine and clonidine ( $\alpha 2$ agonist drugs) as an adjuvant to local anaesthesia in supraclavicular brachial plexus block: A randomised double-blind prospective study. Indian J Anaesth. 2012;56(3):243-243. Available from: https://dx.doi. org/10.4103/0019-5049.98767.

19. Gandhi R, Shah A, Patel I. Use of Dexmedetomidine along with Bupivacaine for brachial plexus block. Nati J Med Res. 2012;2(1):67-69.

20. Kaygusuz K, Kol IO, Duger C, Gursoy S, Ozturk H, Kayacan U, et al. Effects of Adding Dexmedetomidine to Levobupivacaine in Axillary Brachial Plexus Block. Curr Therap Res. 2012;73(3):103-111. Available from: https://dx.doi.org/10. 1016/j.curtheres.2012.03.001.

Copyright: (C) the author(s), 2020. It is an open-access article distributed under the terms of the Creative Commons Attribution License (CC BY 4.0), which permits authors to retain ownership of the copyright for their content, and allow anyone to download, reuse, reprint, modify, distribute and/or copy the content as long as the original authors and source are cited.

How to cite this article: Brahmbhatt N, Mehta S. Study of Comparison of Dexmedetomidine Added to Levobupivacaine versus Alone Levobupivacaine in Supraclavicular Brachial Plexus Blockade. Acad. Anesthesiol. Int. 2020;5(2):43-48.

DOI: dx.doi.org/10.21276/aan.2020.5.2.9

Source of Support: Nil, Conflict of Interest: None declared. 